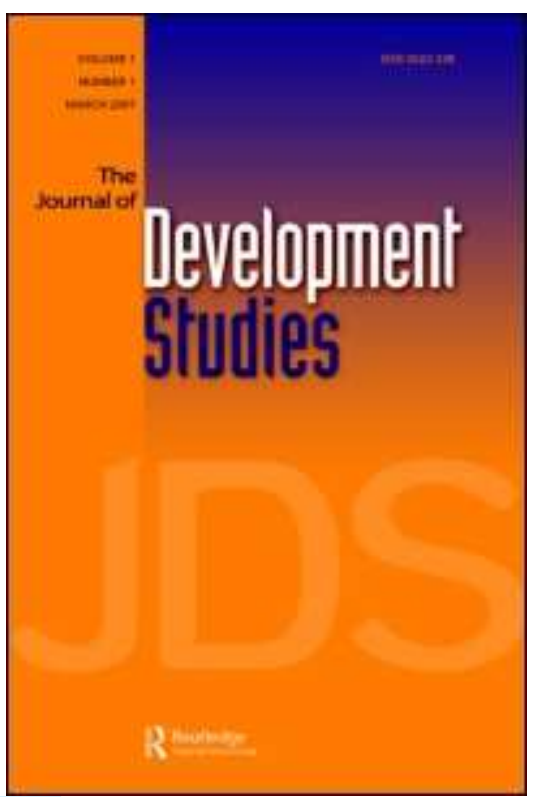

\title{
Farmer Field School in Rural Kenya: A Transformative Learning Experience
}

\begin{tabular}{|r|l|}
\hline Journal: & Journal of Development Studies \\
\hline Manuscript ID: & FJDS-2010-Mar-0014.R2 \\
\hline Manuscript Type: & Original Manuscripts \\
\hline Keywords: & $\begin{array}{l}\text { Livelihoods < Economics, Learning outcomes < Education, } \\
\text { Agriculture < Environmental issues, East Africa < Geographical } \\
\text { Area, Well-being < Health, Community participation < Social Issues }\end{array}$ \\
\hline \hline
\end{tabular}

\section{SCHOLARONE ${ }^{m}$ \\ Manuscripts}


Farmer Field School in Rural Kenya: A Transformative Learning Experience

\begin{abstract}
As participatory agricultural education increases in use, knowledge is needed of its impact on the daily lives of the participants beyond benefits for farming. The purpose of this study was to explore the case of Farmer Field Schools (FFS) under the lens of transformative learning theory, in order to understand the impact that participatory and group-based learning can have on the lives of participants. The findings revealed significant impacts demonstrated by a personal transformation, changes in gender roles and relations, customs and traditions, and community relations, and an increase in household economic development. The implications are relevant both within the fields of rural development and for transformative learning theory.
\end{abstract}

\title{
INTRODUCTION
}

Supporting empowerment and enhancing the citizen's voice in the development process has increasingly become a central element in poverty reduction strategies (World Bank, 2000). Giving increased voice to citizens is thought to have a positive impact on good governance and growth, influencing growth so that it includes the poor and improves the outcomes of development projects (Narayan, 2002; Friis-Hansen, 2004). Further individual and collective agency is required if smallscale farmers are to engage successfully with commodity markets (Barlett, 2005). Farmer education and extension are important components in improving people's lives. However, traditional educational approaches and methods have proved unsuccessful (Anderson and Feder, 2006; Purcell and Anderson, 1997), and efforts to provide farmers with a voice seldom form an integrated part of agricultural programmes (Duveskog, 2006).

In response to this concern, elements of participation and downward accountability have gradually reformed advisory services in agriculture and approaches to participatory extension (World Bank, 2008; Leeuwis, 2004). Alternative approaches have emerged that place the emphasis on farmer groups that provide a 'voice' for the poor (Leeuwis, 2004). However, there is still a great need for mechanisms that can ensure the genuine participation of citizens (Dill, 2009) and improve understanding of how participation can encourage more equal gender relations, since current research indicates that most participatory projects do not lead to significant changes in gender inequalities (Mayoux, 1995). 
An example of an alternative participatory extension approach that seems to address some of these needs is the so-called Farmer Field Schools (FFS), which provide a platform for farmers to meet regularly in groups to study the 'how and why' of farming. There is currently a multitude of FFS initiatives in more than 27 countries in Africa (Braun, et al., 2005) funded by various development agencies.

Published research indicates that FFS is having a substantial impact in terms of increases in farm productivity, reductions in farmers' use of pesticides and improved farming knowledge (Rola, et al., 2002; Praneetvatakul and Waibel, 2003; Mwagi, et al., 2003). Developmental benefits reported include poverty reduction, greater empowerment and collective action (Davis, et al., 2010; Mancini, et al., 2006; Van den Berg and Jiggins, 2007; Züger, 2004). However, outside the economic and agrarian implications of FFS, little is known about its effects on the personal and communal lives of the participants. More specifically, how can the way they think about themselves change as a result of the learning process experienced in FFS? And how does this impact on their household and community relationships? Furthermore, drawing on Percy's (2005) theoretical reflections on 'ways in which...farmers who are engaged in participatory research and extension undergo transformative learning' (p. 127), this study examines this question in considerable depth. Does FFS contribute to a transformative experience, and in such case what is the nature of that transformation (e.g. behaviourally, epistemologically) and how does it impact on farmers' daily lives? Exploring these and similar questions begins to shed light on the transformative nature of participatory education (Percy, 2005) and its impact on the social sphere of rural life. Previous research has shown that educational programmes similar to FFS, which engage participants pedagogically in direct learning experiences and encourage critical reflection on individual experience within the context of group dialogue, often foster transformative learning (Mezirow and Associates, 2009).

In response to this considerations, the aim of this study was twofold: a) to explore how FFS impacts on the daily lives of participants, their family relationships and their relations with other members of the group and the wider community; and b) to explore transformative learning as a possible explanation for the learning and changes that individuals experience from participating in FFS. Extrapolating from the more intangible personal and communal effects could have significant impact on the future expansion and funding of FFS programmes and further substantiate the need for farmer-centred approaches to rural adult education, as well as potentially offering another medium for social and personal growth beyond the narrow confines of development education.

Within the framework of participatory and demand-driven extension (Leeuwis, 2004), hands-on practical learning in FFS emerged as a means of facilitating critical decision+-making 
skills among farmers to deal with complex farming problems (Gallagher, 2003). Consistent with this educational philosophy, FFS uses a learner-centred, problem-based approach to teaching involving field observations, relating observations to the ecosystem, and combining previous experience through group discussion with new information to make informed crop or livestock management decisions (Duveskog, 2006). A group of farmers who meet regularly (usually weekly) in the field form the field school, while plants or animals at the learning site form the main study materials. The learning takes place under the guidance of a trained facilitator, who helps promote active participation, group dialogue and reflection. Critical reflection is promoted through the engagement of comparative experiments and discovery-based activities which stimulate participants further to question preconceived beliefs and norms about farming. Apart from the farming-related content, small-group activities and discussion sessions address 'special topics' relating to non-agricultural issues (e.g., HIV, domestic violence). In addition, song and dances are often used as an additional way to take advantage of local ways of knowing (Duveskog, 2006).

\section{THEORETICAL FRAMEWORK}

In seeking to understand the change in the daily lives of FFS participants, particularly how they make sense of their experience of participatory extension, reflections by Percy (2005) offer a theoretical entry point. Her position is that transformative learning (Mezirow, 2000) provides a lens that sheds light on participatory extension by explaining the nature of change among participants. Transformative learning theory is considered uniquely adult and as situated in human communication, where 'learning is understood as the process of using a prior interpretation to construct a new or revised interpretation of the meaning of one's experience in order to guide future action' (Mezirow, 1996: 162). Based on a constructivist philosophy (e.g., Loveinsohn, et al., 2002), it is rooted in the idea that the individual's world view is framed by structures (e.g., frames of reference) of assumptions that form the basis of the individual's thinking, beliefs, values and actions. This frame of reference both limits and shapes individuals' perceptions, filtering the experiences they choose to give meaning to and how they construct that meaning. Most learning reinforces and elaborates on existing frames of references. For example, farmers in Kenya have a host of beliefs concerning the role of women in farming (e.g., only women plant, weed, collect firewood etc.) and about myths and taboos (e.g. poor crop performance being the result of witchcraft). These beliefs give meaning to their way of farming and are continually reinforced through shared cultural practices. However, some individuals, as result of a significant experience (e.g., education, personal crisis), find their frame of reference inadequate to provide an understanding of the experience and are emotionally provoked to question deeply held 
assumptions. Often a process of dialogue (self, group) and critical reflection on and about these significant experiences leads to what Mezirow (2000: 19) refers to as a 'perspective transformation' or shift in world view. In the likelihood of farmers' transformation, they would begin to relate to their world differently by becoming 'more inclusive, un-discriminating, permeable (open to other viewpoints), critically reflective of assumptions, emotionally capable of change and integrative of experience' (Mezirow, 2000) and as a result take on new roles in life.

Since the early 1980s, the validity of transformative learning theory has been established by extensive research (Taylor, 1998, 2007). Only recently has research started to explore the application of this theory of transformation in non-western settings (Kollins and Hansman, 2005; Ntseane and Merriam, 2008). Furthermore, studies such as Percy's (2005) have noted limitations in applying Mezirow's conception of transformative learning to the understanding of change in nonwestern settings (e.g., over-emphasis on rationality, individual autonomy, lack of appreciation on relational and collective ways of knowing). In response to these concerns, an Afrocentric conception of transformative learning (Asante, 1995; Williams, 2003; Taylor, 2008) has recently emerged (Ntseane and Merriam, 2008: 186). This non-Eurocentric perspective of transformative learning directs attention to the context-dependent nature of significant personal change and foregrounds the local culture of the FFS farmers by increasing awareness of traditional African value systems and their relationship to transformative learning. For example, this means appreciating the importance of understanding human existence in relation to others (Avoseh, 2001, Ntseane, 2005) and recognising that 'most African worldviews emphasise belongingness, connectedness, community participation and people centeredness' (Mkabela, 2005: 180). This Afro-centric perspective was used to inform this research design in the development of interview questions and the analysis of the data, ensuring that the tools used were culturally relevant and appropriate.

\section{METHODOLOGY}

Kakamega District in western Kenya was chosen as a study site because of the presence of a large and well-functioning FFS programme that had been running over a long period of time (more than eight years), thus ensuring a high number of FFS graduates in the area. The important role of agriculture in the region was also a consideration: smallholder farming is the main economic activity in the area and provides important social functions by constituting the rural base for food security. Poverty levels are among the highest in the country, at an estimated 50\% in absolute poverty (Republic of Kenya, 1997), and the economy is largely subsistence-driven. Historically the area is characterised by low input - low output farming. Rainfall is seasonal and permits two 
cropping seasons yearly. The main food crops grown include maize/beans (the staple food), cassava, groundnuts, sweet potatoes, and vegetables such as kale, cabbage and tomatoes. A major cash crop in parts of the district is sugarcane, and one of Kenya's main sugarcane-processing factories is found in the region. The Luhya ethnic group is the main one in the district, with traditionally the extended family and the clan at the centre of their culture. While the culture is rapidly changing with modernisation, there are still strong traditional beliefs and taboos connected to rural life, especially to agriculture, and ties among clan groups are strong. Polygamy is also still practised in the area. Respondents of the study were all involved in subsistence farming, with varying degrees of commercialisation and production for the market, with an average land-holding of 1-4 acres. Interviewees were between 30-55 years of age and mainly belonged to the Luhya ethnic group.

\section{Data Collection and Analysis}

The study used a qualitative design (Merriam, 2002) very similar to most studies of transformative learning (Taylor, 1998, 2007), where the researchers sought to interview both current and past FFS participants who appeared to have undergone a personal change. Individuals were purposely sampled with assistance from local FFS network leaders living in the community and who were familiar with the life stories of most FFS members since before they joined the groups. More specifically, respondents were sampled so as to (a) be informative examples of personal changes resulting from involvement in FFS, (b) represent typical FFS graduates in terms of social and economic characteristics, and (c) to ensure a gender balance among respondents. Twenty individuals were interviewed, half of whom were graduates of FFS from about 2000, while the other half were made up of current FFS members or more recent graduates. The in-depth interviews followed an interview guide developed to ensure that certain questions were covered while permitting flexibility to explore and probe topics of interest to each respondent (Patton, 1990). A cross-cultural team conducted the research, embodying both African and Western values. Efforts were made to establish a rapport and relationships of trust with the respondents prior to holding the interviews, with the researchers spending time in the community, visiting households and farm sites, and attending group learning sessions.

The specific aims of the interviews were to understand (a) respondents' perceptions of their experiences of FFS in terms of both instrumental and personal gains, and (b) changes induced at the personal level (skills and world views) and in respect of relationships at the household/community level following FFS participation. Interpreters were used during the interviews, apart from in a few cases where the interview was carried out in English. Interviews 
lasted between 45 and 60 minutes and were audio-recorded for transcription supplemented by handwritten notes. In the case of interviews carried out in the native language, the transcripts were translated into English prior to data analysis.

In addition to the interviews, direct observations were made during regular meetings of the FFS groups that the interviewees belonged to. These meetings included group discussions, theatrical replays, various group activities, performances of songs and dances, and visits to group experimental fields. Along with individual and group interviews, key informants such as FFS facilitators and FFS network officials were also interviewed to provide background information on the FFS programme. The credibility and trustworthiness of this study was significantly enhanced through triangulation, which involved the use of several data sources (multiple interviews, observations, group interviews and inclusion of informants) to study a single phenomenon (Patton, 2001). In addition, these interviews were conducted in situ, in participants' original homestead setting, thus ensuring greater integrity in the study of participants interpretation of their FFS experience.

All the interviews were transcribed and analysed using a constant comparative approach in which the two groups of respondents were treated the same. The data were separated from the original transcript using NVIVO-QSR (version 8) in order to identify their essential elements. The three researchers systematically reviewed each transcript and coded responses (Miles and Huberman, 1994) in an inductive manner, with themes being developed based on emerging similarities of expression. As a result, common themes were identified and grouped into main themes and sub-themes (Lincoln and Guba, 1985). Analysis continued until there was a consensus on interpretation and each category was 'saturated', that is, further analysis appeared to yield no new information (Lincoln and Guba, 1985). The sub-headings in the findings section of this article represent the overall themes that emerged through this process. For example, sub-themes under the main theme of 'individual change' included skills, personal empowerment, motivation, individual agency, work ethic, well-being before FFS and conception of self. The selected data segments presented below are based on clarity and the portrayal of ideas common to a larger subset of respondents. In order to protect the anonymity of the respondents, pseudonyms have been used in the article.

\section{FINDINGS}


Participants expressed a range of changes in material status, perceptions and behaviours, mainly in connection with their farming activities, but also in relation to personal beliefs, relationships with others and outlook on life in general.

\section{Well-being prior to FFS}

Several interviewees shared the information that they had experienced significant improvements in their well-being as a consequence of joining FFS. To fully appreciate this change and the nature of the transformation, it is important to establish how they made sense of their lives prior to FFS.

Well-being prior to FFS was described in terms of quality of life, the ability to sustain a livelihood and overall self-worth. Many interviewees were food-insecure before joining FFS and unable to nourish and protect their families adequately. They also felt they were wasting time working on other people's farms to earn immediate cash. Sarah, a 47-year-old single mother of six children, stated: 'I used to live a very desperate life. When you don't have food, what do you do? You beg!' Sarah had 2.5 acres of land before joining FFS but did not feel she utilised the land well and therefore could not make a living from it. She also had very low self-esteem after a failed marriage.

Not only did farmers lack the basics necessary to maintain quality of life, they also lacked the power to rectify their situations, and several of the male participants felt bad about not being able to bring up their families effectively. This lack of ability was further affirmed in how participants were viewed by others in their community. As expressed by Titus, a 38-year-old with eight years of schooling who used to work on other people's farms as a casual labourer to earn money for the day: 'In the whole clan people knew me as an absolutely poor person who could not move any stone, and I could do nothing.' He had a one-acre farm but could not grow enough food to last the year for his family of a wife and three children.

Also, farmers' inability to improve their quality of life was inextricably linked to their own self-perceptions. Most significant here was the lack of confidence found among participants, which was associated with an avowed sense of fatalism and a verbal lack of active engagement with the work of living productively. For example, the statement by Priscila, a widowed farmer and single mother, who used to be very poor and experience hunger for more than two months in the year, was shared by many participants: 'I was idle and sat around doing nothing for myself.' Fatalism was also common among participants, as was the thought that being bewitched was the reason for the poor performance of crops and livestock.

Frustration over their livelihoods and aspirations for a better life ultimately became the key motivators for joining FFS. This motivation was enhanced by seeing how others who had joined FFS earlier had improved their lives. 


\section{Transformation of self}

Individual transformation (e.g. significant individual change) found among FFS participants was reflected in an increase in confidence, greater individual agency, a stronger work ethic and commitment to farming, an improved outlook on life, and a greater emphasis on planning and analysis in farming. For example, Herbet, a former FFS group chairman who became a network leader and finally developed enough skills to find employment with a development organisation, spoke about how he had gained confidence in farming as a result of his participation in FFS. He stated: 'I could grow a crop but I could not be sure of the outcome, because I was not even sure myself that I was doing the right thing, but now that I have the knowledge, that experience, I am confident that when I want to grow tomatoes I will be able to handle them.' Herbet's main motivation for joining FFS was his desire to solve any problems he experienced on his farm.

An increase in confidence was also expressed by those who learned to participate actively in the group activities and as a result overcame their shyness when relating to others in their community. Simon, for instance, the secretary of an FFS group and a 32-year-old farmer trying to make a living for his family of a wife and three children on his 1.5-acre plot, demonstrated a greater presence and voice in the clan and family in stating: 'I have gained personality, I have input to the group and my family at large, I can stand and express myself.'

Directly linked to the increase in confidence among participants was a greater sense of individual agency that was reflected in several ways, involving taking the initiative and being prepared. For example, some members used to wait until it started raining before looking for seeds to plant, but now took care to prepare the land, acquire seeds, fertilisers etc. in time to be ready for the rains. Another way in which individual agency emerged was through the questioning of authority. Herbet, the FFS network leader, explained that government officials sometimes saw FFS members as their rivals because the latter were learning to do things without their assistance: 'We were their daughters and sons...so it was a big challenge to learn how to live with them, how to work with them.... It's like he [Ministry of Agriculture officers] does not want you to grow, he wants [you] to remain where you are...knowledge is power.'

An additional indicator of the transformations wrought by FFS members was a stronger work ethic and a greater commitment to farming and to their work. For example, Dismas, a 47year-old FFS Chairman and church leader who runs a small shop business alongside his two-acre farm, spoke of 'a great change: most [members] are serious; when you visit them, you find they have plan for this and that.'

Likewise, Fedelis, a retired school teacher in one of the better off families of the village explained that some men had become more committed to their home and family after joining FFS. 
She stated: 'We have hooked them [the men] from those other wives. They have to concentrate on their projects instead of loitering [and] not having work to do, so men, they are [now] concentrating on what they are supposed to do.'

The change in work ethic experienced by FFS members was mentioned as compatible with the ideals preached by the church. For example, FFS encourages hard workers, just as God does. Several participants interviewed stated that they had experienced greater acceptance by the church after joining FFS, giving them a feeling of being closer to God.

Along with a significant increase in their work ethic, participants also reported an improved outlook on life as a result of participating in FFS, manifested in a sense of greater optimism about farming and happiness and pride in their agricultural achievements.

\section{Changed gender roles and relationships}

Many respondents reported a significant change in their relationship with their spouse in terms of increased sharing, collaboration and joint decision-making and reduced stress. Jafeth, a 53-yearold man with two wives and seven children and one of the few respondents with a secondary education, said: 'FFS brings the two together to share our ideas, and once we reach a solution we now implement as our own: now we own it together. But before a family that has not gone through this process, a man has his own plan and a woman has her own plan.'

This change in marital relations was often seen as something new and different from the traditional culture, in which the man takes most of the decisions. Respondents noted that this was changing and that they had come to realise the need to plan and work together for the benefit of the family.

It seems that the group discussions that take place in FFS act as a trigger for increased discussion and sharing at household level too. For example, Titus stated: 'I took the group discussion to be me, my wife and my family members. I realised "kumbe" [expression of surprise], in most sessions you have to sit down to discuss aspects before you put them in a plan and go to implement them.'

FFS also appears to have contributed to changes in gender roles and habits at the household and community levels. Titus also explained how he came to see the role and capacities of women differently after FFS and realise how limited traditional gender roles were. He mentioned that it was through the FFS group that he realised the potential of women to learn and make clear decisions after observing his fellow group members. And this realisation changed the way he viewed his wife. Simon, 32 years old with a wife and three children, explained that he is now able to do farming activities that are normally seen as women's work. These include planting and 
weeding and even sometimes household chores such as cooking, fetching water and firewood, something he never used to do before.

Likewise, Gabriel, retired, a local farmer and one of the more recent members of FFS, explained that since joining the FFS, members consider each other as family. It is now considered acceptable to be seen visiting or seeking advice from a fellow woman farmer, something not accepted earlier due to restrictions on men talking to the wives of other men. This change in roles and habits was also found among the women.

Similarly, Titus's wife Jenipha, 32 years old with three children, six years of schooling and one of the few women in the community who rides a bicycle, explained that earlier, 'It was assumed that women do not have any mind to organise themselves along economic lines.' In relation to her own changed role she stated further: 'The FFS sittings shifted me from that belief, and I went as an outgoing lady to look for the basic necessities for my own house. I am now currently exploiting the incomes of my household from my own sources.... I am playing the role of a man as well as a woman, so as not just to sit and wait.'

Participants referred to how 'noise' (arguments between husband and wife) in the household had declined following FFS participation, and how there was now more peace in the home. Noise was mainly mentioned as a consequence of financial stress and conflicting priorities in the household. Many members said there was less stress and noise at home due to the increased income, but also because of the more equal power balance that was created when both partners contribute to the upkeep of the family. For example, Jenipha stated;

Sometimes, back before when we were living below the poverty line, there were more quarrels, more suspicion, a lack of confidence between us in the marriage relationship, a lot of noise, a lot of quarrels because I was demanding what he [husband] could not manage at that time. But when we started to graduate from that economy to this level, now we are at par, more equal, and most of our issues are sorted out at the table.

\section{Changed customs and traditions}

Farming practices are often closely connected with traditional beliefs and local customs. Where this was most evident was in relation to gender roles. For example, some farming traditions specify that men should not grow vegetables, women should not plant certain trees such as bananas, eat eggs or chicken, and that only women can plant sweet potatoes. The breaking of some of these taboos is often associated with a high level of fear, even of death, which prevents people from challenging local beliefs and practices. By being able to try out and experiment with certain 
practices in the FFS setting and realising that there were no consequences of doing so, some of these beliefs were now starting to change. Herbet stated: 'Culturally there are some things women are not supposed to do, but when we were in the FFS we did them together and no one has died.' And Sarah said: 'You know, when you are doing something that people don't do and nothing happens, tomorrow somebody will just say, "I saw so and so do it and nothing happened," so you say now let me do it also.' Some participants also believed that witchcraft causes crop failures in agriculture, preventing them from taking action. Through FFS some members came to understand that their poor performance was not due to witchcraft but was simply a matter of crop-management skills.

\section{Changes in community relationships}

All farmers interviewed agreed that their relationship with and status in the community had dramatically changed as a result of their involvement in FFS. Several participants talked about a shift from providing casual labour for other farmers, which is often associated with low community status, to becoming a respected resource person and a leader within the community. For example, Consolata, 54 years old, a retired nurse married to a teacher and cultivating a ten-acre farm with nice cows, explained:
Neighbours [now] come along here to borrow vegetables, to buy produce, or to borrow money. Old relationships [are revived] and new relationships are formed because of the hand-outs. The community views FFS a bit differently because the way we collaborate is unique. The community has noticed that domestic wrangles and chaos have been replaced by peaceful co-existence between families involved in FFS.

Similarly, Priscila continued by explaining how she had gained respect in the community: 'They do not respect me because of property but because of what I am doing on the farm. The relationship with community is different now because they want to tap the knowledge I have. For example, the people in the house want me to teach them what I have learnt. This has brought the community closer to me.'

Many participants also acquire leadership skills which they practise within either the FFS group or the wider community. As Priscila mentioned, 'As a result of FFS I have a position as a leader of family members, also a leader of boda boda (bicycle taxis), and also a leader of youth groups.' Ordinary FFS group members, who had no official leadership positions, often became informal leaders and served as community role models. For example, Sarah used her FFS 
experience to provide input to informal women groups. She stated: 'You go there, you present what you have, you give them the knowledge which you have. It makes me feel humble that the clan thinks of me as somebody special.'

Furthermore, several members explained how FFS had contributed to social inclusion, trust and a sense of togetherness among people in the community. For instance, Joshua, the husband of Fedelis and likewise a retired teacher, said: 'They [the FFS members] talk as a family so that barriers of saying this one has "a" and I don't have "a", this one is richer, this one is poor, that does not exist.' In relation to building trust, Jotham, 52 years old with a wife, ten children and a small shop business that he runs alongside his four-acre farm, mentioned: 'Life has changed, totally changed.... When you are socializing with people, people can trust you, but when you are isolated people cannot trust you because they do not know you. Before FFS, people did not know me.'

\section{From subsistence to farming as a business}

Participants clearly stated that they had acquired benefits from participation in FFS in terms of instrumental learning and skills such as adopting more effective agricultural techniques and the application of new skills on their farms. Participants explained that a shift had taken place in mentality from subsistence farming and providing for the day to a more planned and marketoriented agriculture. Daniel, a 55-year-old FFS chairman who was struggling to support his family from their small half-acre plot, explained how his thinking about farming had changed: 'Previously we were just farming carelessly, but now we are farming for business. When we plant we know we have put in so much, we want to know what will come out so we will compare...we are doing our farming as business.' While previously some participants seemed to rely more on tradition for enterprise selection, after FFS they were able to identify enterprises that had an economic value. Stephen mentioned that he learned the necessity of planning through record keeping:

Through FFS training I learnt the importance of record keeping, and through that I am able to understand whether I have made a loss or a profit. And I can use the records to analyse and see why or where and what caused the loss on my farm and make some simple improvements or changes in my programme.

\section{DISCUSSION}

This study has shown that joining FFS gives participants skills and knowledge stretching beyond the agricultural domain, including aspects of personal development and changes in relationships with others. Understanding the nature of this change warrants discussion of the findings in relation 
to transformative learning theory on the one hand and perspectives regarding poverty eradication and development on the other.

\section{The transformative learning experience among FFS participants}

The results described above indicate that the participants in this study experienced a change in perspective as a result of their participation in FFS, reflected by a significant shift in how they make sense of farming practices and of their lives in general. This shift does not seem to be arbitrary or temporary, but of a profound nature similar to what in transformative learning theory is referred to as perspective transformation (Mezirow, 2000).

One indicator of this shift can be observed in what Kegan (2000) refers to as an epistemological shift, a shift in their way of knowing reflected in greater reliance on planning and analysis in their farming and daily activities. This included a shift away from haphazard unplanned behaviour, recognising that effective farming requires short- and long-term planning, recordkeeping, staying abreast of effective farming practices and the importance of sustained and regular farm management. Further affirming this shift is the questioning by participants of previously held assumptions in terms of taboos and cultural beliefs for explaining farming successes and failures and their replacement by greater reliance on empiricism in informing farming practices. This questioning of assumptions is also indicative of critical reflection, a core element in transformative learning (Mezirow, 2000). This is reflected in Merriam and Netsane's (2008) study in Botswana, where the psychological questioning of the self seemed to overlap with what are referred to as 'sociolinguistic premises involving specific ideologies, prescribed norms and roles, cultural and language codes' (Mezirow, 2001: 144). An example of this is revealed in the transformation of self (psychological) as well as in the change in how the informants in this study perceive gender roles in the family (sociolinguistic).

This transformation or shift in ways of knowing is also indicative of what Lange (2004: 137) refers to as an ontological shift in world view, the transformation of 'an ontological process where participants experience a change in their being in the world including their forms of relatedness'. This relates to individuals' purposefulness, a sense of having greater meaning and direction in life. This was reflected in some of the FFS participants' change from idleness to individual agency and the development of a greater work ethic, both in relationship to farming and in their approach to life in general.

Furthermore, directly associated with the ontological shift is greater self-efficacy and confidence in themselves as farmers and as contributing members of their households and community, consistent with previous research in the field of transformative learning. Instrumental 
gains (e.g., knowledge about farming) in combination with the increase in agency seem to lead to 'a change in meaning perspective and increase in self-confidence in new roles and relationships' (Taylor, 1998: 42). These shifts or changes appear to be interrelated, each contributing to the development of the other.

The findings of epistemological and ontological shifts, as well as greater self-efficacy, are supported by previous studies of transformative learning (Taylor, 1998, 2007), particularly greater self-efficacy (confidence), most of which is based on research conducted in the Western world. This seems to imply that there may be universal constructs of transformative learning that transcend cultural context. However, at the same time, the findings begin to reveal indicators of transformative learning that are unique to the cultural context of Africa. Framed within an Afrocentric perspective of transformative learning, the epistemological shift seems unique to this setting (a shift to empiricism), and not something that has been revealed in any of the Western studies about perspective transformation (Taylor, 2007). This is also similar to the ontological shift revealed in this study, a change in 'forms of relatedness' with others, where participants experienced a change in their status in the community (e.g., leadership) and a greater appreciation of more equitable relationships in their family. Furthermore, in contrast to Western studies of transformative learning the transformation in perspective described by these participants did not emphasise greater autonomy and self-directedness. In future studies there is a need for greater indepth understanding of how reflection takes place in a non-Western setting and the role of metaphors and cultural expressions in triggering the questioning of held assumptions.

In addition to the possibly transformative nature of FFS, the findings also reveal other insights about transformative learning. Assuming the participants experienced a transformation in perspective, this seems to have had a secondary, ripple effect at both the household and community levels. In other words, this study sheds light on the impact of transformative learning beyond the initial educational experience (FFS), including on the participants' everyday lives. For example, changes in gender relations and family roles emerged as a significant result of this transformation in perspective, expressed in terms of a more equal balance of power among men and women in the household setting and in terms of beliefs about men's and women's respective roles in the practice of farming. In particular, this seems to have had a liberating effect on women, as they acquired greater opportunities to engage in decision-making and economic activity. Also, methodologically, this qualitative study provides a more explicit perspective on earlier findings of more quantitative nature about the impact of FFS on participants, particularly women (e.g., Davis, et al., 2005).

While the study does provide some insight in terms of understanding the impact of FFS on the daily lives of participants and their relationships, it also generates additional research questions. 
In particular, the study calls for further investigation into how the various pedagogical aspects of the learning processes within FFS create a transformation perspective and how and in what ways critical reflection takes place.

\section{Implications for development practice}

As a result of the FFS experience, the participants developed more meaning and purpose in their lives, as reflected in their greater optimism, outlook and satisfaction in life. This sense of freedom has an instrumental role in development seen from the point of view of capability, the theoretical basis of UNDP's perspective on poverty (UNDP, 2005), where well-being is achieved through a process of expanding the real freedoms that people can enjoy (Sen, 1999). Furthermore, the increased power and new opportunities for women, which are shown as leading to an increase in household well-being and income, provides valuable input into the global debate on poverty reduction and the role of women in development (World Bank, 2008). Also, it gives support to the notion that 'empowerment requires structural change and an enabling environment. In conjunction with women's ability to make transformative choices these affect not only women's individual lives but the very structures and institutions that have denied them agency in the past' (Hoodfar, 2007: 266).

As previously discussed, secondary or ripple effects in the community were also observed following FFS participation. The fact that participants have taken on leadership functions in the community demonstrates the wide variety of ways in which FFS can influence the daily lives of participants. Study participants experienced an increase in status among their peers as a result of their increased skills and leadership capacities and thus came to serve as informal role models and mentors for others. This is particularly the case in terms of farming knowledge and practices. However, interestingly FFS members also seemed to serve as role models in terms of living up to ideals (formal or informal) about what makes a 'good' man or woman with respect to norms such as working hard, helping others, not depending on alcohol etc. This suggests that FFS can potentially provide an important entry point for rural social change by introducing new ideas, practices and behaviours beyond the technical measures that are often associated with development interventions.

Previous research on FFS has focused almost exclusively on its effectiveness as an approach to promoting the adoption of agricultural innovations. This study, however, indicates that it is the combination of instrumental knowledge (e.g. practices and innovations) and enhanced individual and collective agency acquired through the learning process that enables poor farmers to improve their well-being and agency. The study further indicates a symbiotic relationship between 
confidence and economic status in that, while individual transformation provides the basis for economic development among FFS graduates, such economic development further reinforces the individual's self confidence and status in the community. This calls for further recognition of the close inter-linkages between material and psychological aspects when addressing poverty concerns.

The enhanced agency and analytical skills acquired through the FFS process may prove to be some of the most important contributions of the FFS approach to the livelihoods of poor farmers; as such capabilities are highly advantageous when relating to market forces and local service providers. From the point of view of governments and donor agencies, the fact that FFS appears to encourage active and committed farmers basing their activities on empiricism rather than cultural beliefs may provide opportunities for improving the effectiveness of demand-driven service provision and mechanisms for the genuine participation of citizens in development interventions.

\section{REFERENCES}

Anderson, J. R., Feder, G., Ganguly, S. (2006). The rise and fall of training and visit (T\&V) system: an Asian mini-drama with an African epilogue. World Bank Policy Research Working Paper (3928), (Washington DC: The World Bank).

Avoesh, M. B. M. (2001) Learning to be an active citizen: lessons of traditional Africa for lifelong learning. International Journal of Lifelong Education 20, pp. 479-486.

Asante, M. K. (1987). The Afrocentric idea. (Philadelphia: University Press).

Bebbington, A., Lewis, D., Batterbury, S., Olson, E., and Siddiqi, M. S. (2007) Of Text and Practices: Empowerment and Organisational Cultures in World Bank-funded Rural Development. Journal of Development Studies, 43(4), pp. 597-621.

Barlett, A. (2005) No more adoption rates! Looking for empowerment in agricultural development programme. Impact Assessment Workshop, CIMMYT, Mexico.

Braun, A., Jiggins, J. Röling, N. van den Berg, H. and Snijders, P. (2005) A global survey and review of Farmer Field School experiences. Report, International Livestock Research Institute, Nairobi, Kenya.

Chant, S. (2008) The 'Feminisation of Poverty' and the 'Feminisation' of Anti-Poverty Programmes: Room for Revision? Journal of Development Studies, 44(2), pp.165-197.

Dill, B. (2009) The Paradoxes of Community-based Participation in Dar es Salaam, Development and Change 40(4), pp. 717-743. 
Davis, K., Nkonya, E., Kato, E., Mekonnen, D. A., Odendo, M., and Miiro, R. (2010). Impact of farmer field schools on agricultural productivity and poverty in East Africa. International Food Policy Research Institute. Retrieved on September 22, 2007 from http://www.ifpri.org/sites/default/files/publications/ifpridp00992.pdf

Duveskog, D. (2006) Theoretical perspectives of the learning process in Farmer Field Schools, with reference to East African experiences. A working paper, Swedish University of Agricultural Sciences, Uppsala.

Friis-Hansen, E. (ed.) (2004) Farmer Empowerment: Lessons Learned and Ways Forward. DIIS, Copenhagen.

Friis-Hansen, E. (2008) Impact assessment of farmer institutional development and agricultural change: Soroti district, Uganda. Development in Practice 18(4), pp. 506-523.

Friis-Hansen, E. and Duveskog, D. (2008) Linking the learning process in Farmer Field Schools to impact of transformative change and poverty reduction. Paper presented at the workshop Rethinking Impact: Capturing the complexity of Poverty and Change, International Centre for Tropical Agriculture, Cali (26-28 March).

Gallagher, K. (2003) Fundamental elements of a Farmer Field School. LEISA Magazine 05(6), pp. 5-6. ILEIA.

Hellin, J. and Dixon, J. (2008) Operationalising Participatory Research and Farmer-to-Farmer Extension: the Kamayoq in Peru. Development in Practice, 18 (4-5), pp. 627-632.

Hoodfar, H. (2007) Women, Religion, and the 'Afghan Education Movement' in Iran. Journal of Development Studies, 43(2), pp. 265-293.

Kegan, R. (2000) What 'Forms' Transforms? A Constructive-Developmental Approach to Learning, in: Mezirow, J. and Associates (eds.) Learning As Transformation (San Francisco, CA: Jossey-Bass), pp. 35-70.

Kollins, J. M. and Hansman, C. A. (2005) The role of women in popular education in Bolivia: a case study of the "Oficina Jurídica Para La Mujer". Adult Basic Education 15, pp. 3-20.

Lange, E. (2004) Transformative and Restorative Learning: A Vital Dialectic for Sustainable Societies. Adult Education Quarterly 54, pp. 121-139.

Leeuwis, C. (2004) Communication for Rural Innovation: Rethinking agricultural extension. (Blackwell Science Inc.) 
Loevinsohn, M. E., Berdegué, J. A. and Guijt, I. (2002) Deepening the basis of rural resource management: learning processes and decision support. Agricultural Systems 73, pp. 3-22.

Lincoln, Y. and Guba, E. (1985) Naturalistic Inquiry. (New York: Sage).

Mancini, F., van Bruggen, A.H.C., and Jiggins, J.L.S. (2006) Evaluating the integrated pest management (IPM) farmer field school outcomes using the sustainable livelihoods approach in India, in: F. Mancini (ed.). Impact of integrated pest management farmer field schools on health, farming systems, the environment, and livelihoods of cotton growers in Southern India, pp 69-84. Published doctoral dissertation, Wageningen University, the Netherlands.

Mayoux, L. (1995) Beyond Naivety: Women, Gender Inequality and Participatory Development, Development and Change 26(2), pp. 235-258.

Merriam, S. B., and Associates (2002) Qualitative research in practice. (San Francisco: JosseyBass).

Mezirow, J. (1996) Contemporary Paradigms of Learning. Adult Education Quarterly, 46, pp. 158172.

Mezirow, J. and Associates (eds.). (2000) Learning as transformation. (San Francisco: JosseyBass).

Mezirow, J., Taylor, E. W., and Associates (2009) Transformative Learning in Practice. (San Francisco: Jossey-Bass).

Miles, M. and A. Huberman (1994) Qualitative Data Analysis. (Thousand Oaks, Sage, California). Mkabela, Q. (2005) Using Afrocentric methods in researching indigenous African culture. Qualitative Report 10, pp. 178-189.

Mwagi, G. O., Onyango, C. A., Mureithi, J.G., and Mungai, P. C. (2003) Effectiveness of FFS approach on technology adoption and empowerment of farmers: a case of farmer groups in Kisii District, Kenya, in; KARI NAL (ed.) Proceedings of the $21^{\text {st }}$ Annual Conference of the Soil Science Society of East Africa, Eldoret, Kenya, pp. 467-475.

Narayan, D. (2002) Empowerment and Poverty Reduction: A Sourcebook. (Washington D.C.: World Bank).

Ntseane, G. P. (2005) Indigenous people and learning: the case of African indigenous education, in R. Hill and R. Keily (eds.). Proceedings of the $46^{\text {th }}$ Annual Adult Education Research Conference, University of Georgia, Athens, GA, pp. 469-476.

Ntseane, G. P. and Merriam, S. B. (2008) Transformational learning in Botswana: how culture shapes the process. Adult Education Quarterly 58, pp. 183-197.

Quinnan, T. (1997) Adult students “at-risk:” culture bias in higher education. (Westport, CT:

Bergin and Garvey). 
Patton, M. Q. (1990) Qualitative Evaluation Research Methods, 2nd edition. (Newbury Park, California: Sage Publications).

Percy, R. (2005) The contribution of transformative learning to the practice of participatory research and extension: theoretical reflections. Agriculture and Human Values 22, pp. $127-$ 136.

Praneetvatakul, S. and Waibel, H. (2003) A socio-economic analysis of Farmer Field Schools (FFS) implemented by the national programme on integrated pest management of Thailand. Paper presented at the CIMMYT impact assessment conference, CIMMYT, San Jose, Costa Rica (4-7 February, 2002).

Purcell, D. L. and J. R. Anderson (1997) Agricultural extension and research: achievements and problems in national systems. (Washington DC: The World Bank).

Republic of Kenya. (1997) Welfare Monitoring Survey III. Central Bureau of Statistics, Office of the Vice-President and Ministry of Planning and National Development. (Nairobi: Government Printers).

Rola, A. C., Jamias, S.B., and Quizon, J.B. (2002) Do Farmer Field School graduates retain and share what they learn? An investigation in Iloilo, Philippines. Journal of International Agricultural and Extension Education 9, pp. 65-76.

Sen, A. (1999) Development as freedom. (Oxford: Oxford University Press).

Sones, K. and Duveskog, D. (2003) Farmer Field Schools: the Kenyan experience. Report of the Farmer Field Schools stakeholder forum held at ILRI, Nairobi. FAO/KARI/ILRI, Nairobi.

Taylor, E. W. (1997) Building upon the theoretical debate: a critical review of the empirical studies of Mezirow's transformative learning theory. Adult Education Quarterly 48, pp. 32-57.

Taylor, E. W. (1998) Transformative learning: a critical review. ERIC Clearinghouse on Adult, Career, \& Vocational Education. Information Series No. 374.

Taylor, E. W. (2007) An update of transformative learning theory: a critical review of the empirical research (1999-2005). International Journal of Lifelong Education 26, pp. 173-191.

Taylor, E. W. (2008) Transformative learning theory, in: S. B. Merriam (ed.), New directions for adult and continuing education. An update of adult learning 119, (San Francisco: Jossey-Bass). pp. $5-15$

UNDP, Human Development Report (2005) (New York: Oxford University Press).

van den Berg, H. and Jiggins J. (2007) Investing farmers: the impacts of Farmer Field Schools in relation to integrated pest management. World Development 35, pp. 663-686.

Williams, H. S. (2003) Black mama sauce: integrating the theatre of the oppressed and Afrocentricity in transformative learning, in; C. A. Wiessner, S. R. Meyer, N. L. Pfhal, and P. G. 
Neaman (eds.). Proceedings of the Fifth International Conference on Transformative Learning, NY: Columbia University, Teachers College, New York.

World Bank (2000) World Development Report 2000/2001: Attacking Poverty. (Oxford University Press, World Bank).

World Bank (2008) World Development Report 2008: Agriculture for Development. (Washington D.C.: World Bank).

Züger, R. (2004) Impact assessment of Farmer Field Schools in Cajamarca, Peru: an economic evaluation. Social Sciences Working Paper No. 2004-1. International Potato Centre, Lima. 